\section{Clarithromycin versus levofloxacin-based regimens for Helicobacter pylori eradication in the Kurdistan Region of Iraq: A randomized clinical trial}

\author{
Shinah A. Mohammed, ${ }^{1}$ \\ Omer Q. B. Al-lela, 1,2 \\ Nawfal R. Hussein, ${ }^{3}$ \\ Ramadhan S. Hajany, ${ }^{4}$ \\ Laween S. Alduhoky 5 \\ ${ }^{1}$ College of Pharmacy, University of \\ Duhok, Duhok, Kurdistan Region; \\ ${ }^{2}$ Department of Pharmacy, Al-Noor \\ University College; ${ }^{3}$ College of \\ Medicine, University of Zakho, \\ Kurdistan Region; ${ }^{4}$ College of Medicine, \\ University of Duhok, Duhok, Kurdistan \\ Region; ${ }^{5}$ Azadi Teaching Hospital, \\ Duhok, Kurdistan Region, Iraq
}

\begin{abstract}
Helicobacter pylori infection is a predisposing factor for gastric cancer. This prospective, randomized clinical trial aimed to compare $H$. pylori eradication rates associated with a clarithromycin-based regimen and levofloxacin-based regimen. H. pylori infection was confirmed by a rapid urease test during endoscopy and its eradication by a urea breath test. In this study, 192 patients were recruited; 93 patients received a clarithromycin-based regimen and 99 a levofloxacin-based regimen. Sixty-four patients completed the clarithromycinbased regimen and 60 the levofloxacinbased regimen. The eradication success rate of the clarithromycin-based regimen was $52 / 64(81.25 \%)$, while that of the levofloxacin-based regimen was 49/60 $(81.6 \%) \quad(\mathrm{P}=0.9524 ; \quad$ odds ratio $[\mathrm{OR}]=1.0280$; confidence interval $[\mathrm{CI}]=0.4153-2.5447)$. Investigation of the risk factors associated with treatment failure showed that the overall efficacy of the regimens was influenced by body mass index (BMI), with a high failure rate observed in patients with a high BMI $(\mathrm{P}=0.0174 ; \quad \mathrm{OR}=1.1116 ; \quad \mathrm{CI}=1.0187-$ 1.2129). Age, sex, endoscopic diagnosis and smoking did not influence treatment outcomes. Further studies are needed to monitor H. pylori antibiotic resistance rates.
\end{abstract}

\section{Introduction}

Helicobacter pylori is a Gram-negative microaerophilic bacterium, ${ }^{1}$ the discovery of which changed the mainstream understanding of gastric diseases, particularly peptic ulcer. ${ }^{1}$ Infection with $H$. pylori predisposes one to gastric cancer - the third most commonly occurring cause of cancerrelated death. ${ }^{2}$ A total of $50 \%$ of the world's population has $H$. pylori infection, ${ }^{3}$ with a prevalence rate of $20 \%$ in developed countries and $80 \%$ in developing countries. ${ }^{3}$ While several regimens have been considered for $H$. pylori eradication, the failure rates associated with eradication are high, varying across countries. With the increased prevalence of antibiotic resistance, $H$. pylori eradication represents a challenge. Different variables such as patient characteristics, underlying disease presence and environmental factors also play an important role in treatment failure. Triple therapy, comprising amoxicillin and clarithromycin plus a proton pump inhibitor, is the most commonly used first-line regimen recommended for the eradication of H. pylori. ${ }^{4}$ However, owing to increases in the rates of H. pylori resistance to clarithromycin, the efficacy of this regimen has been progressively decreasing. ${ }^{4}$ Levofloxacin - a fluoroquinolone - was then proposed as an effective and safe second-line medication for the eradication of this bacterium. ${ }^{5}$ In a study conducted in Iraq that used molecular methods to detect both clarithromycin and levofloxacin resistance, $16.2 \%$ of the strains were resistant to clarithromycin, while $4 \%$ were resistant to levofloxacin. ${ }^{6}$ No study in Iraq has investigated the eradication success rates associated with the clarithromycin and levofloxacin-based regimens. This study was conducted to investigate the eradication success rate of these two regimens and identify the risk factors associated with $H$. pylori eradication failure.

\section{Materials and Methods}

\section{Study design and patients}

We conducted a prospective, randomized clinical trial between July 2018 and March 2019 at the Gastrointestinal Disease Center of the Azadi Teaching Hospital, Duhok, Kurdistan Region of Iraq. Patients' $H$. pylori infection status was confirmed using a rapid urease test during endoscopy. The inclusion criteria for patient recruitment were: H. pylori-positivity, age 18 years and older, and provision of consent for recruitment. Exclusion criteria included: prior antibiotic use, age younger than 18
Correspondence: Omer Qutaiba Bader Aldeen Al-lela, College of Pharmacy, University of Duhok, Duhok, Kurdistan Region, Iraq.

Tel. +964.7717494296.

E-mail: omarallela@yahoo.com

Key words: Helicobacter pylori; Eradication Levofloxacin; Clarithromycin; Duhok; Iraq.

Contributions: the research was conducted by SAM and supervised by OQBA and NRH. The research project was designed by SAM, OQBA and NRH. The ethical approval was obtained by SAM. Data collection was done by SAM, EGD (esophagogastroduodenoscopy) was performed by RSH and LSA; patients were followed-up by SAM, RSH and LSA. OQBA and NRH contributed in the statistical analysis. All the authors read and approved the final manuscript.

Conflict of interest: the authors declare no potential conflict of interest.

Funding: none.

Received for publication: 27 July 2019. Accepted for publication: 16 August 2019.

This work is licensed under a Creative Commons Attribution NonCommercial 4.0 License (CC BY-NC 4.0).

(C) Copyright: the Author(s), 2019

Licensee PAGEPress, Italy

Gastroenterology Insights 2019; 10:8256 doi:10.4081/gi.2019.8256

years, pregnancy, and the absence of consent for participation. At the end of the study, eradication success rate was determined using intention-to-treat and per-protocol analyses.

\section{Intervention}

Participants were randomly allocated to two groups by computer-generated assignment. Recruited patients received either: i) clarithromycin-based triple therapy, comprising clarithromycin $500 \mathrm{mg}$ administered twice daily after meals plus omeprazole 20 mg twice daily before meals, and amoxicillin $1 \mathrm{~g}$ twice daily after meals for 14 days; ii) levofloxacin-based triple therapy, comprising levofloxacin $500 \mathrm{mg}$ administered once a day after meals plus omeprazole $20 \mathrm{mg}$ twice daily before meals and amoxicillin $1 \mathrm{~g}$ twice daily after meals for 14 days.

Participants were interviewed and provided instructions on how to take the drugs correctly.

The primary outcome of our project was H. pylori eradication. All participants were invited to undergo a $14 \mathrm{C}$-urea breath test, 
four weeks after treatment completion. During the test, patients were given a capsule containing $37 \mathrm{kBq}(1 \mu \mathrm{Ci})$ 14-carbon urea, with $20 \mathrm{~mL}$ lukewarm water after at least 5 hours of fasting. At 3 min post-dose, the patients consumed $20 \mathrm{~mL}$ of lukewarm water. At $10 \mathrm{~min}$ post-dose, they were asked to take a deep breath, hold it for approximately 5-10 sec, and then exhale into a breath-card (Heliprobe, Kibion).

The secondary outcomes were compliance and side effects. All participants were instructed to report any side effects associated with medication intake. Patients were instructed on medication use and provided a date for the confirmation of $H$. pylori eradication. All patients were contacted by a pharmacist one week after drug administration initiation and at the end of the treatment period. Drug compliance and adverse events were evaluated by a pharmacist.

\section{Statistics}

The eradication rate associated with each regimen was calculated as the percentage of participants with a negative urea breath test among patients who completed the treatment course. Chi-square and Fisher's exact tests were used to compare dichotomous data, and regression analyses were utilized for numerical data. The SPSS 21.0 statistical software (IBM Corp., Armonk, NY, USA) was used for statistical analysis.

\section{Ethics}

The research proposal was approved by the ethics committee of the College of Pharmacy, and the ethics unit in the Directorate of Health, Duhok, Kurdistan Region of Iraq. Consent was obtained from all participants.

\section{Results}

\section{Patient characteristics, compliance, and side effects}

We recruited 192 patients who visited Azadi Teaching Hospital's Gastrointestinal Disease Center. The average age of the patients was $37.5 \pm 14.3$ (Table 1). Of the total patients, 93 received the clarithromycin-based regimen while 99 received the levofloxacin-based regimen. In the clarithromycin group, three patients could not complete the treatment course due to severe gastrointestinal side effects; in the levofloxacin group, no cases of treatment discontinuation were reported due to the severity of adverse effects (Figure 1). All patients except for those who were lost to follow-up and those who could not tolerate the regimen were assessed using the 14Carbon urea breath test after treatment conclusion. Overall, 124 patients completed the treatment course: 64 in the clarithromycin group and 60 in the levofloxacin group. Regarding side effects in the patients with treatment course completion, 55/64 $(85.93 \%)$ of those in the clarithromycin group developed side effects compared to the $4 / 60(6.6 \%)$ in the levofloxacin group (Fisher's exact test, $\mathrm{P}=0.001$ ).

\section{H. pylori eradication rates}

A total of 124 patients were involved in the analysis of $H$. pylori eradication rates. The average age of the recruited participants was $37.3 \pm 14.2$ years. Of them, 48 $(38.7 \%)$ were male and $77(61.3 \%)$ were female. While the eradication success rate in the clarithromycin-based regimen was $52 / 64(81.25 \%)$, that in the levofloxacinbased regimen was $49 / 60 \quad(81.6 \%)$ $(\mathrm{P}=0.9524$; odds ratio $[\mathrm{OR}]=1.0280$; confidence interval $[\mathrm{CI}]=0.4153-2.5447)$.

Table 1. Characteristics of the participants.

\begin{tabular}{lccc} 
Features & OAC & OAL & Total \\
BMI (mean \pm SD) kg/m² & $26.06 \pm 5.4$ & $25.74 \pm 4.7$ & $25.9 \pm 5.06$ \\
Age (mean \pm SD) y & $37.3 \pm 14.2$ & $37.68 \pm 14.9$ & $37.5 \pm 14.3$ \\
\hline Sex & $45(56.96 \%)$ & $34(43.03 \%)$ & 79 \\
$\quad$ Male no. (\%) & $48(42.5 \%)$ & $65(57.5 \%)$ & 113 \\
$\quad$ Female no. (\%) & $18(41.9 \%)$ & $25(58.1 \%)$ & 43 \\
Endoscopic diagnosis & $75(50.3 \%)$ & $74(49.7 \%)$ & 149 \\
$\quad$ PUD no. (\%) & $24(61.5 \%)$ & $15(38.5 \%)$ & 39 \\
$\quad$ None PUD no. (\%) & $55(85.93 \%)$ & $4(6.6 \%)$ & 59 \\
\hline Smoking no. (\%) & $(64 / 93) 68.8 \%$ & $(60 / 99) 60.6 \%$ & 124 \\
Side effects no. (\%) & &
\end{tabular}

$\mathrm{OAC}$, clarithromycin $500 \mathrm{mg}$ administered twice daily after meals plus omeprazole $20 \mathrm{mg}$ twice daily before meals, and amoxicillin $1 \mathrm{~g}$ twice daily after meals for 14 days; OAL, levofloxacin $500 \mathrm{mg}$ once a day after meals plus omeprazole $20 \mathrm{mg}$ twice daily before meals, and amoxicillin $1 \mathrm{~g}$ twice daily after meals for 14 days; BMI, body mass index; SD, standard deviation; no., number of patients; (\%), percentage of patients; PUD, peptic ulcer disease.

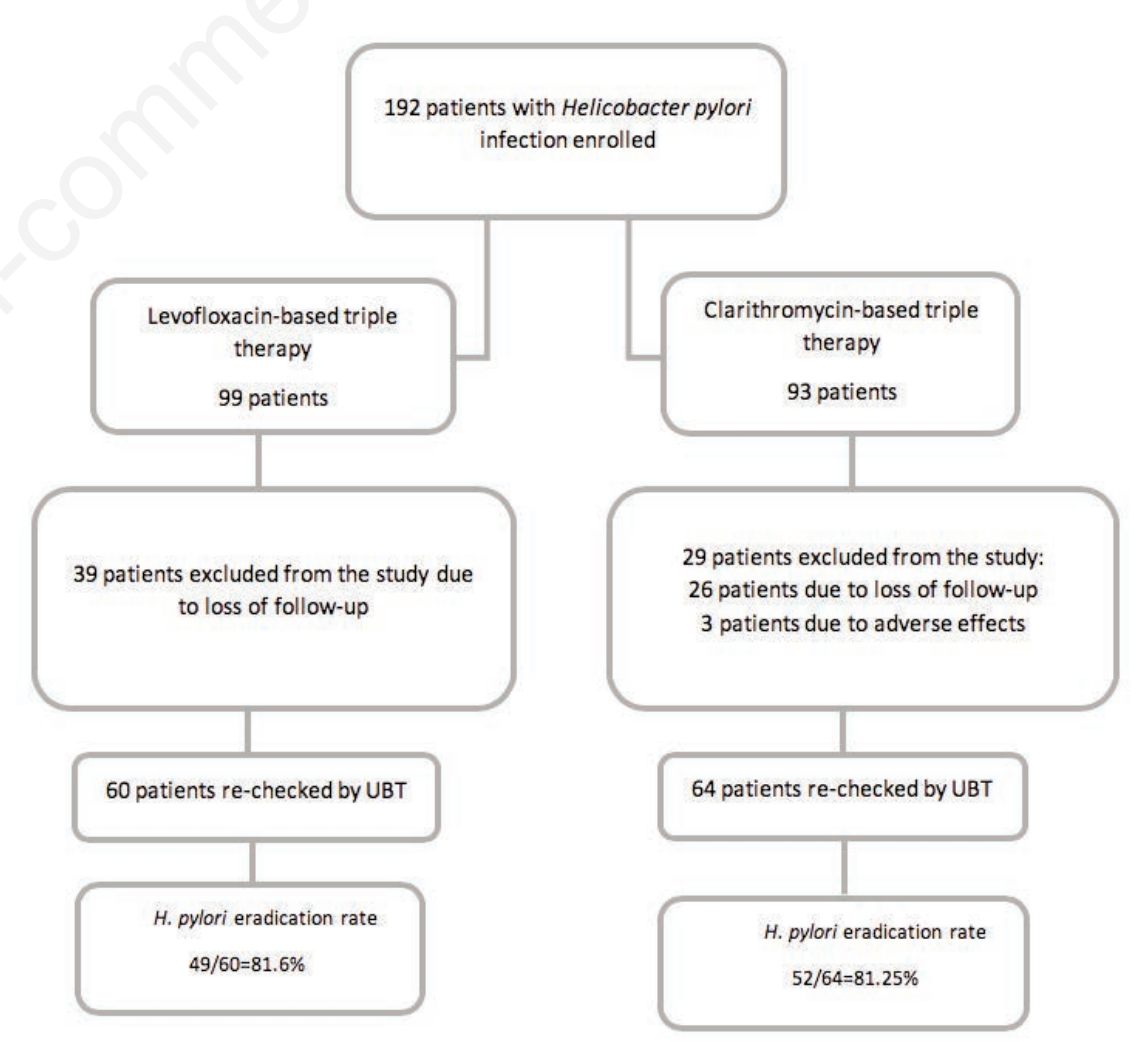

Figure 1. Study flow diagram. UBT, 14C-urea breath test. 


\section{Factors associated with failure}

First, we studied the risk factors for failure in terms of overall eradication in both regimens. The overall efficacy of the regimens was influenced by the body mass index (BMI), with high failure rates observed in patients with a high BMI $(\mathrm{P}=0.0174 ; \quad \mathrm{OR}=1.1116 ; \quad \mathrm{CI}=1.0187-$ 1.2129) (Table 2).

The efficacy of either regimen was not influenced by sex, age, smoking and endoscopy diagnosis. We further classified our patients into two groups, by regimen. Then, we compared the subgroups of patients to investigate the effects of differ- ent factors on individual regimens. Treatment outcomes in the clarithromycinbased regimen were influenced by BMI, with high failure rates observed in those with a high BMI (Table 3).

Other factors did not show any effects on the eradication rate. Regarding the levofloxacin-based regimen, BMI, age, sex, smoking and endoscopy diagnosis did not influence outcomes (Table 4).

\section{Discussion}

H. pylori infection occurs commonly in
Iraq, ${ }^{7}$ with a prevalence rate of around $80 \%$ in the adult population. ${ }^{8}$ This infection is associated with peptic ulcer disease and gastric carcinoma. ${ }^{9}$ The treatment of $H$. pylori infection using successful eradication methods may improve the clinical outcomes of patients. ${ }^{1}$ However, the antibiotic-resistance of $H$. pylori has been increasing progressively, resulting in high eradication failure rates. ${ }^{10}$ Antibiotic resistance is markedly recognized in developing countries. ${ }^{10}$ Therefore, to choose appropriate antibiotics regimens for the treatment of $H$. pylori, continuous monitoring of antibiotic sensitivity patterns is mandatory. As the clar-

Table 2. Risk factors for Helicobacter pylori eradication failure.

\begin{tabular}{|c|c|c|c|c|c|}
\hline Factor & Success & Failure & P-value & OR & CI \\
\hline BMI (mean \pm SD) kg/m² & $25.6 \pm 5.1$ & $28.6 \pm 5.3$ & $0.017 *$ & 1.1 & $\begin{array}{l}1.018 \\
1.212\end{array}$ \\
\hline Age $($ mean \pm SD $)$ y & $37.4 \pm 15.06$ & $36.9 \pm 9.9$ & 0.9 & 0.96 & $0.9660-1.0302$ \\
\hline Smoking no. (\%) & $21(80.7 \%)$ & $5(19.3 \%)$ & 0.9 & 1.05 & $0.3518-3.1828$ \\
\hline $\begin{array}{l}\text { Sex } \\
\quad \text { Male no. (\%) } \\
\text { Female no. (\%) }\end{array}$ & $\begin{array}{l}42(87.5 \%) \\
59(77.6 \%)\end{array}$ & $\begin{array}{c}6(12.5 \%) \\
17(22.4 \%)\end{array}$ & 0.17 & 0.5 & $0.18-1.3631$ \\
\hline $\begin{array}{l}\text { Endoscopy } \\
\text { PUD no. (\%) } \\
\text { None-PUD no. (\%) }\end{array}$ & $\begin{array}{l}27(93.1 \%) \\
74(77.9 \%)\end{array}$ & $\begin{array}{c}2(6.9 \%) \\
21(22.1 \%)\end{array}$ & 0.08 & 0.26 & $0.057-1.1885$ \\
\hline
\end{tabular}

OR, odds ratio; CI, confidence interval; BMI, body mass index; SD, standard deviation; no., number of patients; (\%), percentage of patients; PUD, peptic ulcer disease. Statistical test (biochemical logistic regression). *Significance set at $\mathrm{P}<0.05$.

Table 3. Risk factors for of Helicobacter pylori eradication failure in the clarithromycin-based regimen.

\begin{tabular}{|c|c|c|c|c|c|}
\hline Factor & Success & Failure & P-value & OR & CI \\
\hline BMI $($ mean $\pm \mathrm{SD}) \mathrm{kg} / \mathrm{m}^{2}$ & $25.99 \pm 4.96$ & $29.9 \pm 6.5$ & $0.038 *$ & 1.14 & $1.0074-1.2949$ \\
\hline Age $($ mean \pm SD) y & $38.42 \pm 14.81$ & $37.33 \pm 12.6$ & 0.8 & 0.99 & $0.9512-1.0399$ \\
\hline Smoking no. (\%) & $15(88.2 \%)$ & $2(11.8 \%)$ & 0.4 & 0.49 & $0.0964-2.5240$ \\
\hline $\begin{array}{l}\text { Sex } \\
\quad \text { Male no. (\%) } \\
\quad \text { Female no. }(\%)\end{array}$ & $\begin{array}{l}26(89.6 \%) \\
26(74.3 \%)\end{array}$ & $\begin{array}{l}3(10.4 \%) \\
9(25.7 \%)\end{array}$ & 0.12 & 0.33 & $0.0810-1.3724$ \\
\hline $\begin{array}{l}\text { Endoscopy } \\
\text { PUD no. (\%) } \\
\text { None-PUD no. (\%) } \\
\end{array}$ & $\begin{array}{l}13(86.7 \%) \\
39(79.6 \%) \\
\end{array}$ & $\begin{array}{c}2(13.3 \%) \\
10(20.4 \%)\end{array}$ & 0.54 & 0.6 & $0.1161-3.1018$ \\
\hline
\end{tabular}

OR, odds ratio; CI, confidence interval; BMI, body mass index; SD, standard deviation; no., number of patients; (\%), percentage of patients; PUD, peptic ulcer disease. Statistical test (logistic regression). *Significance set at $\mathrm{P}<0.05$.

Table 4. Risk factors for Helicobacter pylori eradication failure in the levofloxacin-based regimen.

\begin{tabular}{|c|c|c|c|c|c|}
\hline Factor & Success & Failure & P-value & OR & CI \\
\hline $\mathrm{BMI}(\mathrm{mean} \pm \mathrm{SD}) \mathrm{kg} / \mathrm{m}^{2}$ & $25.22 \pm 5.3$ & $27.3 \pm 3.5$ & 0.23 & 1.08 & $0.9515-1.2283$ \\
\hline Age $($ mean \pm SD) y & $36.30 \pm 15.4$ & $36.5 \pm 6.6$ & 0.97 & 1 & $0.9553-1.0483$ \\
\hline Smoking no. (\%) & $6(66.7 \%)$ & $3(33.3 \%)$ & 0.22 & 2.7 & $0.5546-13.0223$ \\
\hline $\begin{array}{l}\text { Sex } \\
\text { Male no. (\%) } \\
\text { Female no. (\%) }\end{array}$ & $\begin{array}{l}16(84.2 \%) \\
33(80.5 \%)\end{array}$ & $\begin{array}{l}3(15.8 \%) \\
8(19.5 \%)\end{array}$ & 0.73 & 0.77 & $0.1805-3.3139$ \\
\hline $\begin{array}{l}\text { Endoscopy } \\
\qquad \text { PUD no. (\%) } \\
\text { None-PUD no. (\%) }\end{array}$ & $\begin{array}{c}14(100 \%) \\
35(76 \%)\end{array}$ & $\begin{array}{l}0(0.0 \%) \\
11(24 \%)\end{array}$ & 0.053 & 1 & $0.99-1.1$ \\
\hline
\end{tabular}

OR, odds ratio; CI, confidence interval; BMI, body mass index; SD, standard deviation; no., number of patients; (\%), percentage of patients; PUD, peptic ulcer disease. Statistical test (logistic regression). 
ithromycin-based regimen is generally used as a first-line regimen for the eradication of H. pylori,${ }^{4}$ the associated resistance rate has been studied thoroughly. In Turkey, the clarithromycin resistance rate ranges from $16.4 \%$ to $48.2 \%{ }^{11}$ while in Iran, it ranges from $1.4 \%$ to $26.5 \%{ }^{12}$ In Saudi Arabia, the clarithromycin resistance rate was $21 \%,{ }^{13}$ while in Iraq, the value was $16.2 \% .{ }^{6}$ Owing to increases in the rates of clarithromycin resistance, levofloxacin was considered as a salvage treatment for $H$. pylori eradication; ${ }^{5}$ however, several reports have shown strong resistance to levofloxacin. In a study conducted in Iran, the levofloxacin resistance rate was higher than $20 \%$, while in Iraq, the value was $4 \%$. In our study, the eradication success rate of the clarithromycin-based regimen was $81.25 \%$, which was almost similar to that of the levofloxacin-base regimen $(81.6 \%)$. This indicates that both regimens can be used in the Kurdistan Region of Iraq, particularly owing to the low side effect rate reported in the study. However, as the clarithromycin-based regimen was associated with higher rates of side effects, the levofloxacin-based regimen can be used as the first line of treatment. Additionally, continuous monitoring is mandatory for the investigation of the trends of antibiotic resistance. In a large multicenter project recruiting patients from a center in Egypt and two centers in Saudi, which compared the clarithromycin and levofloxacin-based regimens, the eradication rates were $78.6 \%$ and $84.7 \%$, respectively. ${ }^{14}$ In a study conducted in Iran, the H. pylori eradication rate in patients receiving the clarithromycinbased regimen was $51.7 \%$, which was lower than that associated with the levofloxacinbased regimen $(75 \%) .{ }^{15}$ In another study conducted in China, the H. pylori eradication rate associated with the clarithromycin triple regimen was $75 \%$ vs the eradication rate of $83 \%$ for the levofloxacin-based regimen. ${ }^{16}$ In a study conducted in India that recruited patients with peptic ulcer perforation, the $H$. pylori eradication rate was $79 \%$ in the clarithromycin group vs $87 \%$ in the levofloxacin group. ${ }^{17}$ Additionally, in Venezuela, the $H$. pylori eradication rate associated with clarithromycin triple therapy was $67 \%$ vs $95 \%$ for levofloxacin-based regimens. ${ }^{18}$

Various factors may influence H. pylori eradication, with Broutet et al. identifying a significant association between age and treatment failure. ${ }^{19}$ In another study conducted in Korea that recruited 1,413 patients, female sex and smoking were associated with treatment failure. ${ }^{20}$ In the same study, age did not affect eradication rates. In China, age, sex, endoscopic diagnosis and smoking did not show any effect on treatment success rates. ${ }^{21}$ An Israeli study showed that the H. pylori eradication rate was higher in non-smokers than smokers. ${ }^{22}$ In a meta-analysis studying the effect of smoking as a factor associated with treatment failure, the eradication failure rates were significantly higher among smokers than non-smokers. ${ }^{23}$ In a study conducted in France that studied the factors associated with eradication failure, smoking was associated with high failure rates. ${ }^{19}$ In the same study, peptic ulcer disease was identified as a risk factor for treatment failure. In Greece, age, sex, smoking and ulcer disease showed no effect in terms of $H$. pylori eradication rate. ${ }^{24}$ In our study, age, sex, smoking and endoscopic diagnosis did not influence treatment outcomes. The impact of BMI on $H$. pylori eradication is controversial. In a study comparing 40 overweight/obese participants and 41 normal-weight participants, weight showed a negative effect on H. pylori eradication rates. ${ }^{25}$ However, no difference in the $H$. pylori eradication rate was observed when the eradication rate was studied in various subgroups by BMI. ${ }^{25}$ In our study, the $H$. pylori eradication rate was higher in patients with a high BMI.

\section{Conclusions}

In conclusion, this study indicates that both clarithromycin and levofloxacin-based regimens are associated with high success rates and can be used in the Kurdistan Region of Iraq for $H$. pylori eradication. $H$. pylori eradication was not associated with age, sex, endoscopic diagnosis and smoking. A high BMI was shown to be associated with high eradication failure rates. Further studies are needed to monitor $H$. pylori antibiotic resistance rates.

\section{References}

1. Atherton JC. The pathogenesis of helicobacter pylori induced gastro-duodenal diseases. Annu Rev Pathol 2006;1:63-96.

2. Hussein NR. Helicobacter pylori and gastric cancer in the Middle East: a new enigma? World J Gastroenterol 2010; 16:3226-34.

3. Logan RPH, Walker MM. Epidemiology and diagnosis of Helicobacter pylori infection. BMJ 2001;323:920-2.

4. Yeo YH, Shiu SI, Ho HJ, et al. First-line Helicobacter pylori eradication therapies in countries with high and low clarithromycin resistance: a systematic review and network meta-analysis. Gut
2018;67:20-7.

5. Peedikayil MC, AlSohaibani FI, Alkhenizan AH. Levofloxacin-based first-line therapy versus standard firstline therapy for Helicobacter pylori eradication: Meta-analysis of randomized controlled trials. PLoS One 2014;9:e85620.

6. Hussein NR, Tunjel I, Majed HS, et al. Duodenal ulcer promoting gene 1 (dupA1) is associated with A2147G clarithromycin-resistance mutation but not interleukin- 8 secretion from gastric mucosa in Iraqi patients. New Microbes New Infect 2015;6:5-10.

7. Hussein NR, Napaki SM, Atherton JC. A study of Helicobacter pylori-associated gastritis patterns in Iraq and their association with strain virulence. Saudi J Gastroenterol 2009;15:125-7.

8. Hussein NR, Robinson K, Atherton JC. A study of age-specific Helicobacter pylori seropositivity rates in Iraq. Helicobacter 2008;13:306-7.

9. Hussein NR, Mohammadi M, Talebkhan Y, et al. Differences in virulence markers between Helicobacter pylori strains from Iraq and those from Iran: potential importance of regional differences in H. pylori-associated disease. J Clin Microbiol 2008;46:1774-9.

10. Megraud F. The challenge of Helicobacter pylori resistance to antibiotics: the comeback of bismuth-based quadruple therapy. Therap Adv Gastroenterol 2012;5:103-9.

11. Kocazeybek B, Tokman HB. Prevalence of primary antimicrobial resistance of H. pylori in Turkey: A systematic review. Helicobacter 2016;21:251-60.

12. Manzouri L, Zarei F, Niazi N, Sedaghattalab M. Comparison of the success rate of quadruple and triple antibiotic therapy in eradicating Helicobacter pylori infection in Southwest of Iran: A randomized clinical trial. Int J Infect 2017;4:e15610.

13. Marie MAM. Patterns of Helicobacter pylori resistance to metronidazole, clarithormycin and amoxicillin in Saudi Arabia. J Bacteriol Virol 2008;38:1738.

14. Assem M, El Azab G, Rasheed MA, et al. Efficacy and safety of Levofloxacin, Clarithromycin and Esomeprazol as first line triple therapy for Helicobacter pylori eradication in Middle East. Prospective, randomized, blind, comparative, multicenter study. Eur J Intern Med 2010;21:310-4.

15. Moradniani M, Mirbeik-Sabzevari Z, Jaferian S, et al. Levofloxacin based vs clarithromycin based sequential therapy 
in helicobacter pylori eradication; a randomized clinical trial. Gastroenterol Hepatol Bed Bench 2018;11;19-26.

16. Cheng $\mathrm{H}, \mathrm{Hu}$ FL, Zhang GX. [Levofloxacin-based triple therapy for first-line Helicobacter pylori eradication treatment: a multi-central, randomized, controlled clinical study]. Zhonghua Yi Xue Za Zhi 2010;90:7982.

17. Gopal R, Elamurugan TP, Kate V, et al. Standard triple versus levofloxacin based regimen for eradication of Helicobacter pylori. World J Gastrointest Pharmacol Ther 2013;4:23-7.

18. Dib J Jr, Alvarez B, Mendez L, Cruz ME. Efficacy of PPI, levofloxacin and amoxicillin in the eradication of Helicobacter pylori compared to conventional triple therapy at a Venezuelan hospital. Arab J Gastroenterol 2013;14:123-5.

19. Broutet N, Tchamgoué S, Pereira E, et al. Risk factors for failure of Helicobacter pylori therapy results of an individual data analysis of 2751 patients. Aliment Pharmacol Ther 2003;17:99-109.

20. Kim SE, Park MI, Park SJ, et al. Trends in Helicobacter pylori eradication rates by first-line triple therapy and related factors in eradication therapy. Korean J Intern Med 2015;30:801-7.

21. Huh CW, Youn YH, Jung DH, et al. Early attempts to eradicate Helicobacter pylori after endoscopic resection of gastric neoplasm significantly improve eradication success rates. PLoS One 2016;11:e0162258.

22. Itskoviz D, Boltin D, Leibovitzh $\mathrm{H}$, et al. Smoking increases the likelihood of
Helicobacter pylori treatment failure. Dig Liver Dis 2017;49:764-8.

23. Suzuki T, Matsuo $\mathrm{K}$, Ito $\mathrm{H}$, et al. Smoking increases the treatment failure for Helicobacter pylori eradication. Am J Med 2006;119:217-24.

24. Georgopoulos SD, Ladas SD, Karatapanis S, et al. Factors that may affect treatment outcome of triple Helicobacter pylori eradication therapy with omeprazole, amoxicillin, and clarithromycin. Dig Dis Sci 2000;45:63-7.

25. Abdullahi M, Annibale B, Capoccia D, et al. The eradication of Helicobacter pylori is affected by body mass index (BMI). Obes Surg 2008;18:1450-4. 